\title{
Supply chain resilience and its interplay with digital technologies: making innovations work in emergency situations
}

\section{Supply chain resilience and its interplay with digital technologies: making innovations work in emergency situations}

Resilience in supply chains is as vital for firms as immune systems are for human beings. Immune systems continuously monitor, anticipate and adapt to dynamic environments. Similarly, resilience capabilities in supply chains (SC) enable recovery and adaptation when the SC are exposed to and affected by changes in environmental and operational factors (MacCarthy et al., 2016). One such significant and rapidly emerging change is digitalization in firms and in society (Richey et al., 2016, Ivanov et al., 2019c; Panetto et al., 2019). Supply chain resilience (SCR), as a capability, is both challenged and enhanced by digitalization. Although the concept of resilience in supply chain management (SCM) is not new (Pettit et al., 2010; Blackhurst et al., 2011; Brandon-Jones et al., 2014; Hohenstein et al., 2015; Chowdhury and Quaddus, 2017; Hosseini et al., 2019; Xu et al., 2020), ongoing developments in digital technologies have been introduced fairly recently in the field of SCR and have not yet been well explored (Papadopoulos et al., 2017; Dubey et al., 2021; Ivanov et al., 2019a, b; Queiroz et al., 2019; Brintrup et al., 2020; Lohmer et al., 2020; Ralston and Blackhurst, 2020).

Innovations in digital technologies influence the development of new paradigms, principles and models in SCM in general, and SCR in particular. We consider digital technology as a combination of Industry 4.0, the Internet of Things (IoT), Big Data analytics, artificial intelligence, advanced tracking and tracing technologies, wearables and additive manufacturing (Baryannis et al., 2019; Büyüközkan and Göçer, 2018; Ben-Daya et al., 2019; Ivanov et al., 2020; Frazzon et al., 2021). Accompanying such technological advances in managing SCR are similar advances in organizational practice and culture, involving the socio-technical aspects of new technology use. Moreover, the outbreak of coronavirus disease 2019 (COVID-19) virus and the associated global pandemic showed that firms with an extensive utilization of digital technologies could operate with more resilience due to enhanced visibility and co-ordination (Ivanov, 2020a; Ivanov and Das, 2020; Queiroz et al., 2020).

The interplay of SCR and digital technologies can be considered in light of three dimensions.

\section{Change in traditional SC designs}

The first dimension is the change in traditional SC designs, and the resulting change in SCR management. For example, additive manufacturing applications may result in redesigning global SC production and sourcing strategy. Industry 4.0 enables individualization of products and services that frequently requires SC re-design (Ivanov et al., 2016; Frank et al., 2019). How resilient are those new structures? Can existing SCR management principles and methods cope with new realities? How can digitalization be used to achieve SC "resileanness", i.e. a combination of resilient and lean? (Ivanov and Dolgui, 2019).

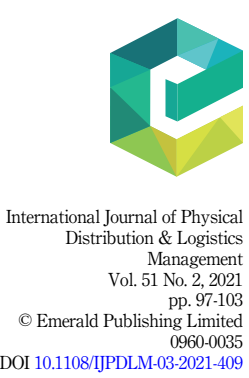


IJPDLM

51,2

\section{SC visibility and digital twin}

The second dimension is SC visibility. Big data analytics applications to SCM have been seen in retail, procurement processes, manufacturing, omnichannel promotion actions, real-time traffic operation monitoring and proactive safety management. Blockchain applications to SCs are emerging (Min, 2019; Dolgui et al., 2020b). The central objective of data analytics is to increase visibility, response time and efficiency in the SC (Lohmer et al., 2020; Yoon et al., 2019). Similarly advances in sensor technology and IoT have enabled heightened awareness and visibility in the SC. How can SC visibility be better utilized to increase SCR? Organizations are exploring ways to utilize large volumes of data to both predict risks and assess vulnerability (Choi et al., 2018) and improve the resilience of SC operations (Choi and Lambert, 2017). Das et al. (2019) and Dubey et al. (2021) provide empirical insights on the multiple interplays between digital data technologies and SCR. Ivanov and Dolgui (2020a) present a framework of a digital SC twin to manage the SCR.

\section{$\mathrm{SC}$ relationships and technology}

The third dimension concerns the softer and equally important aspect of digitalization and SCR - relationships and technology. Organizational innovations such as SC towers, dynamic buyer-supplier relationships, technology investment reward sharing structures and humantechnology interface and co-management issues typify such issues. Dubey et al. (2021) note that digital technologies may significantly influence agility, adaptability and alignment, and their impact on performance of SCs. New principles and models are required to investigate potential interactions between digitalization and SCR in this dimension.

The central research questions of this special issue are therefore as follows:

(1) the nature and drivers of potential inter-relationships between digitalization and SCR;

(2) the performance implications of digitalization for SCR;

(3) the impact of digitalization on SCR management principles and organizational and operational practices;

(4) the nature of digitalization technology-based extensions associated with SCR in factories of the future.

Industry 4.0, additive manufacturing and data analytics open new opportunities, but also create new challenges for SCR. While the applications of digital technologies to SCM are exemplarily spread out engineering and management journals, there is a paucity of research that conceptualizes and generalizes new SCR concepts and practices that may be associated with, and enabled by digitalization. For example, big data analytics may reduce supply and demand risks through enhanced SC visibility and forecast accuracy, reduction in information disruption risks and better quality of contingency plan activation. Advanced trace and tracking systems may facilitate integrated SC planning and reduce supply and time risks through real-time co-ordination in activating contingency policies. SCs are typically protected against anticipated disruptions using means such as risk mitigation inventory, capacity reservation and backup sources. Such remedies are expensive and difficult to justify especially when disruptions do not happen for extended periods of time. Blockchain systems could help reduce these inefficiencies, creating a record of activities and data needed for recovery in terms of synchronized contingency plans. Similarly, additive manufacturing can reduce the need for risk mitigation inventory and capacity reservations, including identifying and maintaining backup contingent suppliers. The decentralized control principles in Industry 4.0 systems make it possible to diversify risks and reduce the need for structural SC redundancy with the help of manufacturing flexibility. SC visibility afforded by digitalization can accelerate reaction and recovery times, with quicker deployment of proactive contingency plans. 
Another aspect of SCR is the ripple effect (Ivanov et al., 2014, 2019b; Kinra et al., 2020; Dolgui et al., 2020a; Garvey and Carnovale, 2020; Li and Zobel, 2020). Big data analytics and advanced trace and tracking systems in general, and blockchain technology in particular, can help trace the roots of disruptions, observe disruption propagation (i.e. the ripple effect) (Dolgui et al., 2018; Li et al., 2020) select short-term stabilization actions based on a clear understanding of what capacities and inventories are available (emergency planning) to help develop mid-term recovery policies, and enable examine and analyse the long-term performance impact of disruption ripple effects. Additive manufacturing could simplify and reduce the number of $\mathrm{SC}$ nodes and layers and thus mitigating disruption propagation in the SC. These and related research concepts and relationships call for rigorous research inquiry.

Despite initial efforts to gain new insights about the impact of digital technologies on SC risks (Papadopoulos et al., 2017; Dolgui et al., 2018; Ivanov, 2018; Cavalcantea et al., 2019; Dubey et al., 2021; Ivanov and Dolgui, 2020b), the understanding of the individual contribution and the interplay of different digital technologies on specific SC and operations resilience is not well understood. In addition, the usage of digital technologies in overarched SCR perspectives such as viability is an understudied research area (Dolgui et al., 2020c; Hosseini et al., 2020; Ivanov, 2020b; Ivanov and Dolgui, 2020c). The special issue intends to advance the body of knowledge in this regard by soliciting relevant, well-designed and rigorously executed research.

This special issue contains a clutch of four carefully chosen, rigorous papers with welldefined and significant contributions to the area of SCR and digitalization. Zouari et al. (2021) present a study entitled "Does digitalising the supply chain contribute to its resilience?" The authors consider SCR a key concept for managers who wish to develop the capacity to enhance the ability of their SCs using digital tools to achieve greater visibility, anticipation and collaboration. The purpose of this paper is to investigate the link between SCR and SC digitalisation. The results were analysed using an ordinary least squares regression model based on a sample of 300 managers in the field of SC management. The findings suggest that $\mathrm{SC}$ digitalisation is characterised by the degree of digital maturity and the adoption of digital $\mathrm{SC}$ tools. Both the degree of digital maturity and the adoption of digital tools have a positive impact on SCR, but the degree of digital maturity matters more for the smaller companies. Offering practical implications, the authors conclude that managers should reflect on the need to continue digitalising their SCs and focus primarily on digital maturity degree, rather than digital SC tool adoption, if they want greater SCR in the current uncertain environment.

The study by Nguyen et al. (2021) "Risk identification and modeling for blockchainenabled container shipping" analyses potential operational risks of blockchain-integrated container shipping systems. Using literature review, the authors construct a directed acyclic graph (DAG), and analyse the results based on network topological metrics. 28 potential risks and 47 connections were identified in three groups of initiative, transitional and sequel. The DAG analysis results reflect a relatively well-connected network of identified hazardous events, suggesting the pervasiveness of information risks and various multiple-event risk scenarios. The criticality of the connected systems' security and information accuracy is also indicated. The paper indicates the changes of container shipping operational risk in the process of blockchain integration by using updated data.

Paul and Chowdhury (2021) develop in their paper "Production recovery plan in manufacturing supply chains for a high-demand item during COVID-19" a quantitative model for production recovery for a high-demand and essential item during the COVID-19 pandemic. They also analyse the properties of the recovery plan and optimize the recovery plan to maximize the profit in the recovery window. The result shows that the developed recovery model is capable of revising the production plan in the situations of both demand and supply disruptions and improving the profit for the manufacturers. The authors discuss 
IJPDLM

51,2

100

managerial implications, including the roles of digital technologies in the recovery process. The model can support decision-makers of high-demand and essential items to make an accurate and prompt decision in designing the revised production plan to recover under pandemic-like conditions.

Doetzer and Pflaum (2021) analyse in their paper "The role of digitalized informationsharing for flexibility capability utilization: Lessons from Germany and Japan” the role of information sharing as an enabler to utilize flexibility capabilities before and after SC disruptions. They aim to provide indications on how digitalized information sharing enhances flexibility capability utilization. The findings suggest that the enhancement of estimated transport time accuracy, based on digitalized information-sharing (DIS) and partmatrixes, supports rapid supplier and transport mode adjustment. Second, the authors reveal that while the effects of DIS in manufacturing are limited without pre-existing flexibility capabilities, steady internal and external DIS utilizes existing manufacturing flexibility to cope with disruptions beyond production. Third, it is suggested that track and trace technologies enhance the value of shared data and allow flexibility in the form of demandoriented distribution, but companies unable to adopt technologies can still enhance flexibility capabilities with DIS using the existing infrastructure.

In summary, this special issue presents insightful initial research to lay the groundwork and stimulate further research efforts to build knowledge about the emergent phenomena of SCR and digitalization.

\section{Dmitry Ivanov Supply Chain and Operations Management, Berlin School of Economics and Law, Berlin, Germany \\ Jennifer Blackhurst Management Sciences, The University of Iowa, Iowa City, Iowa, USA, and \\ Ajay Das Operations Management, Baruch College - CUNY, New York, New York, USA}

\section{References}

Baryannis, G., Validi, S., Dani, S. and Antoniou, G. (2019), "Supply chain risk management and artificial intelligence: state of the art and future research directions", International Journal of Production Research, Vol. 57 No. 7, pp. 2179-2202.

Ben-Daya, M., Hassini, E. and Bahroun, Z. (2019), "Internet of things and supply chain management: a literature review", International Journal of Production Research, Vol. 57 Nos 15-16, pp. 4719-4742.

Blackhurst, J., Dunn, K.S. and Craighead, C.W. (2011), "An empirically derived framework of global supply resiliency", Journal of Business Logistics, Vol. 32 No. 4, pp. 374-391.

Brandon-Jones, E., Squire, B., Autry, C.W. and Petersen, K.J. (2014), "A contingent resource-based perspective of supply chain resilience and robustness", Journal of Supply Chain Management, Vol. 50 No. 3, pp. 55-73.

Brintrup, A., Pak, J., Ratiney, D., Pearce, T., Wichmann, P., Woodall, P. and McFarlane, D. (2020), "Supply chain data analytics for predicting supplier disruptions: a case study in complex asset manufacturing", International Journal of Production Research, Vol. 58 No. 11, pp. 3330-3341.

Büyüközkan, G. and Göçer, F. (2018), "Digital Supply Chain: literature review and a proposed framework for future research", Computers in Industry, Vol. 97, pp. 157-177.

Cavalcantea, I.M., Frazzon, E.M., Forcellinia, F.A. and Ivanov, D. (2019), "A supervised machine learning approach to data-driven simulation of resilient supplier selection in digital manufacturing", International Journal of Information Management, Vol. 49, pp. 86-97. 
Choi, T.-M. and Lambert, J.H. (2017), “Advances in risk analysis with big data”, Risk Analysis, Vol. 37 No. 8, pp. 1435-1442.

Choi, T.-M., Wallace, S.W. and Wang, Y. (2018), "Big data analytics in operations management", Production and Operations Management, Vol. 27 No. 10, pp. 1868-1883.

Chowdhury, M.M.H. and Quaddus, M. (2017), "Supply chain resilience: conceptualization and scale development using dynamic capability theory", International Journal of Production Economics, Vol. 188, pp. 185-204.

Das, A., Gottlieb, S. and Ivanov, D. (2019), "Managing disruptions and the ripple effect in digital supply chains: empirical case studies", in Ivanov, D. et al. (Eds), Handbook of the Ripple Effects in the Supply Chain, Springer, New York, pp. 261-285.

Doetzer, M. and Pflaum, A. (2021), "The role of digitalized information-sharing for flexibility capability utilization: lessons from Germany and Japan", International Journal of Physical Distribution and Logistics Management, in press.

Dolgui, A., Ivanov, D. and Sokolov, B. (2018), "Ripple effect in the supply chain: an analysis and recent literature", International Journal of Production Research, Vol. 56 Nos 1-2, pp. 414-430.

Dolgui, A., Ivanov, D. and Rozhkov, M. (2020a), "Does the ripple effect influence the bullwhip effect? An integrated analysis of structural and operational dynamics in the supply chain", International Journal of Production Research, Vol. 58 No. 5, pp. 1285-1301.

Dolgui, A., Ivanov, D., Potryasaev, S., Sokolov, B., Ivanova, M. and Werner, F. (2020b), "Blockchain-oriented dynamic modelling of smart contract design and execution control in the supply chain", International Journal of Production Research, Vol. 58 No. 7, pp. 2184-2199.

Dolgui, A., Ivanov, D. and Sokolov, B. (2020c), "Reconfigurable supply chain: the X-network", International Journal of Production Research, Vol. 58 No. 13, pp. 4138-4163.

Dubey, R., Gunasekaran, A., Childe, S.J., Wamba, S.F., Roubaud, D. and Foropon, C. (2021), "Empirical investigation of data analytics capability and organizational flexibility as complements to supply chain resilience", International Journal of Production Research, Vol. 59 No. 1, in press.

Frank, A.G., Dalenogare, L.S. and Ayala, N.F. (2019), "Industry 4.0 technologies: implementation patterns in manufacturing companies", International Journal of Production Economics, Vol. 210, pp. 15-26.

Frazzon, E.M., Freitag, M. and Ivanov, D. (2021), "Intelligent methods and systems for decisionmaking support: toward digital supply chain twins", International Journal of Information Management. doi: 10.1016/j.ijinfomgt.2020.102281.

Garvey, M.D. and Carnovale, S. (2020), "The rippled newsvendor: a new inventory framework for modelling supply chain risk severity in the presence of risk propagation", International Journal of Production Economics, Vol. 228, doi: 10.1016/j.ijpe.2020.107752.

Hohenstein, N.-O., Feisel, E., Hartmann, E. and Giunipero, L. (2015), "Research on the phenomenon of supply chain resilience A systematic review and paths for further investigation", International Journal of Physical Distribution and Logistics Management, Vol. 45 Nos 1-2, pp. 90-117.

Hosseini, S., Ivanov, D. and Dolgui, A. (2019), "Review of quantitative methods for supply chain resilience analysis”, Transportation Research: Part E, Vol. 125, pp. 285-307.

Hosseini, S., Ivanov, D. and Blackhurst, J. (2020), “Conceptualization and measurement of supply chain resilience in an open-system context", IEEE Transactions on Engineering Management. doi: 10. 1109/TEM.2020.3026465.

Ivanov, D. (2018), Structural Dynamics and Resilience in Supply Chain Risk Management, Springer, New York.

Ivanov, D. (2020a), "Predicting the impact of epidemic outbreaks on global supply chains: a simulation-based analysis on the coronavirus outbreak (COVID-19/SARS-CoV-2) case", Transportation Research - Part E, Vol. 136, doi: 10.1016/j.tre.2020.101922. 
IJPDLM

51,2
Ivanov, D. (2020b), "Viable supply chain model: integrating agility, resilience and sustainability perspectives-lessons from and thinking beyond the COVID-19 pandemic", Annals of Operations Research. doi: 10.1007/s10479-020-03640-6.

Ivanov, D. and Das, A. (2020), "Coronavirus (COVID-19/SARS-CoV-2) and supply chain resilience: a research note", International Journal of Integrated Supply Management, Vol. 13 No. 1, pp. 90-102.

Ivanov, D. and Dolgui, A. (2019), "Low-Certainty-Need (LCN) Supply Chains: a new perspective in managing disruption risks and resilience2", International Journal of Production Research, Vol. 57 Nos 15-16, pp. 5119-5136.

Ivanov, D. and Dolgui, A. (2020a), "A digital supply chain twin for managing the disruption risks and resilience in the era of Industry 4.0", Production Planning and Control. doi: 10.1080/09537287. 2020.1768450 .

Ivanov, D. and Dolgui, A. (2020b), "Viability of intertwined supply networks: extending the supply chain resilience angles towards survivability: a position paper motivated by COVID-19 outbreak", International Journal of Production Research, Vol. 58 No. 10, pp. 2904-2915.

Ivanov, D. and Dolgui, A. (2020c), "OR-methods for coping with the ripple effect in supply chains during COVID-19 pandemic: managerial insights and research implications", International Journal of Production Economics. doi: 10.1016/j.jpe.2020.107921.

Ivanov, D., Dolgui, A. and Sokolov, B. (2019a), "The impact of digital technology and Industry 4.0 on the ripple effect and supply chain risk analytics", International Journal of Production Research, Vol. 57 No. 3, pp. 829-846.

Ivanov, D., Dolgui, A. and Sokolov, B. (Eds) (2019b), Handbook of Ripple Effects in the Supply Chain, Springer, New York.

Ivanov, D., Sokolov, B., Dolgui, A., Werner, F. and Ivanova, M. (2016), "A dynamic model and an algorithm for short-term supply chain scheduling in the smart factory Industry 4.0", International Journal of Production Research, Vol. 54 No. 2, pp. 386-402.

Ivanov, D., Tang, C.S., Dolgui, A., Battini, D. and Das, A. (2020), "Researchers' perspectives on Industry 4.0: multi-disciplinary analysis and opportunities for operations management", International Journal of Production Research. doi: 10.1080/00207543.2020.1798035.

Kinra, A., Ivanov, D., Das, A. and Dolgui, A. (2020), "Ripple effect quantification by supply risk exposure assessment", International Journal of Production Research, Vol. 58 No. 19, pp. 5559-5578.

Li, Y. and Zobel, C.W. (2020), "Exploring supply chain network resilience in the presence of the ripple effect", International Journal of Production Economics, Vol. 228, doi: 10.1016/j.ijpe.2020.107693.

Li, Y., Chen, K., Collignon, S. and Ivanov, D. (2020), "Ripple effect in the supply chain network: forward and backward disruption propagation, network health and firm vulnerability", European Journal of Operational Research. doi: 10.1016/j.ejor.2020.09.053.

Lohmer, J., Bugert, N. and Lasch, R. (2020), "Analysis of resilience strategies and ripple effect in blockchain-coordinated supply chains: an agent-based simulation study", International Journal of Production Economics, Vol. 228, doi: 10.1016/j.ijpe.2020.107882.

MacCarthy, B.L., Blome, C., Olhager, J., Srai, J.S. and Zhao, X. (2016), "Supply chain evolution - theory, concepts and science", International Journal of Operations and Production Management, Vol. 36 No. 12 , pp. $1696-1718$.

Min, H. (2019), "Blockchain technology for enhancing supply chain resilience", Business Horizons, Vol. 62 No. 1, pp. 35-45.

Nguyen, S., Chen, P.S.-L. and Du, Y. (2021), "Risk identification and modeling for blockchain-enabled container shipping", International Journal of Physical Distribution and Logistics Management. doi: 10.1108/IJPDLM-01-2020-0036.

Panetto, H., Iung, B., Ivanov, D., Weichhart, G. and Wang, X. (2019), "Challenges for the cyberphysical manufacturing enterprises of the future", Annual Reviews in Control, Vol. 47, pp. 200-213. 
Papadopoulos, T., Gunasekaran, A., Dubey, R., Altay, N., Childe, S.J. and Wamba, S.F. (2017), "The role of Big Data in explaining disaster resilience in supply chains for sustainability", Journal of Cleaner Production, Vol. 142 No. 2, pp. 1108-1118.

Paul, S.K. and Chowdhury, P. (2021), "A production recovery plan in manufacturing supply chains for a high-demand item during COVID-19", International Journal of Physical Distribution and Logistics Management. doi: 10.1108/IJPDLM-04-2020-0127.

Pettit, T.J., Fiksel, J. and Croxton, K.L. (2010), "Ensuring supply chain resilience: development of a conceptual framework", Journal of Business Logistics, Vol. 31 No. 1, pp. 1-21.

Queiroz, M.M., Pereira, S.C.F., Telles, R. and Machado, M.C. (2019), "Industry 4.0 and digital supply chain capabilities", Benchmarking: An International Journal. doi: 10.1108/BIJ-12-2018-0435.

Queiroz, M.M., Ivanov, D., Dolgui, A. and Wamba, S.F. (2020), "Impacts of epidemic outbreaks on supply chains: mapping a research agenda amid the COVID-19 pandemic through a structured literature review", Annals of Operations Research. doi: 10.1007/s10479-020-03685-7.

Ralston, P. and Blackhurst, J. (2020), "Industry 4.0 and resilience in the supply chain: a driver of capability enhancement or capability loss?", International Journal of Production Research, Vol. 58 No. 16, pp. 5006-5019.

Richey, R.G., Morgan, T.R., Lindsey-Hall, K. and Adams, F.G. (2016), "A global exploration of big data in the supply chain", International Journal of Physical Distribution and Logistics Management, Vol. 46 No. 8, pp. 710-739.

Yoon, J., Talluri, S., Yildiz, H. and Sheu, C. (2019), "The value of Blockchain technology implementation in international trades under demand volatility risk", International Journal of Production Research. doi: 10.1080/00207543.2019.1693651.

Zouari, D., Ruel, S. and Viale, L. (2021), "Does digitalising the supply chain contribute to its resilience?", International Journal of Physical Distribution and Logistics Management, forthcoming. 